Original Article

\title{
The effect of chest expansion resistance exercise in chronic stroke patients: a randomized controlled trial
}

\author{
Chang-Beom Kim, PT, MS ${ }^{1)}$, Jun-Ho Shin, PT, MS ${ }^{1)}$, Jong-Duk Choi, PT, $\mathrm{PhD}^{2)^{*}}$ \\ 1) Department of Physical Therapy, Graduate School, Daejeon University, Republic of Korea \\ 2) Department of Physical Therapy, College of Natural Science, Daejeon University: 62 Daehak-ro, \\ Dong-gu, Daejeon 300-716, Republic of Korea
}

\begin{abstract}
Purpose] The aim of this study was to examine the initial effects of chest expansion resistance exercise (CERE) applied to chronic stroke patients on their pulmonary functions, chest expansion, and functional gait ability. [Subjects] Forty chronic stroke patients without any respiration-related rehabilitation program experience (21 men and 19 women; times elapsed since occurrence of stroke: $21.8 \pm 5.3$ months) were randomly and equally allocated to a CERE group (experimental group) and a control group. [Methods] An ordinary stroke rehabilitation program was performed on the subjects. While the experimental group received a CERE intervention, the control group performed passive range of motion exercise with automatic instruments. [Results] The CERE group's chest expansion significantly increased after the intervention, whereas the control group did not see any significant difference. As regards VC (vital capacity), FVC (forced vital capacity), and $\mathrm{FEV}_{1}$ (forced expiratory volume in one second), there were no significant changes in either the CERE or control group. In the 10MTWT (10-meter timed walking test), there were no significant changes in either group, but in the 6MWT (6-minute walk test), while there were no significant differences in the control group, the CERE group saw significant changes. [Conclusion] The results of application of CERE to chronic stroke patients demonstrated the importance of respiratory exercise in an approach to stroke rehabilitation treatment intervention and the need to add respiratory exercise to a rehabilitation intervention program.
\end{abstract}

Key words: Breathing, PNF, Stroke

(This article was submitted Jul. 10, 2014, and was accepted Sep. 2, 2014)

\section{INTRODUCTION}

In hemiplegia patients, weakened respiratory muscles in relation to chest expansion cause fatigue or dyspnea when performing tasks that demand intensive efforts ${ }^{1-3)}$, and such patients may have problems with activities of daily living ${ }^{4}$. A combined program of rehabilitation and respiration-related intervention would be effective in enhancing stroke patients' functional activities, such as gait ${ }^{5,6)}$.

Accordingly, this study aimed to examine exercise tolerance of chronic stroke patients with hemiplegia when chest expansion resistance exercises (CERE) facilitating respiratory function was applied to them prior to a functional rehabilitation intervention by looking at its effects on their respiratory function, chest expansion, and gait function which requires muscle endurance.

*Corresponding author. Jong-Duk Choi (E-mail: choidew@ dju.kr)

(C2015 The Society of Physical Therapy Science. Published by IPEC Inc. This is an open-access article distributed under the terms of the Creative Commons Attribution Non-Commercial No Derivatives (by-ncnd) License $<$ http://creativecommons.org/licenses/by-nc-nd/3.0/>.

\section{SUBJECTS AND METHODS}

The subjects of this study were 40 chronic stroke patients who had been diagnosed and hospitalized with a stroke at a rehabilitation hospital and were receiving a stroke rehabilitation treatment. Patients who had normal cognitive functions (scores $>24$ on the mini-mental state examination) and therefore could understand the content of this research and the reasoning behind it, who could walk more than 10 meters and for more than six minutes, and who had not received respiration-related rehabilitation previously were considered to be eligible for this research. All of the protocols used in this study were approved by the University of Daejeon. Before participation, the procedures, risks, and benefits were explained to all the participants, who gave their informed consent. The participants' rights were protected according to the guidelines of the University of Daejeon.

The 40 chronic stroke patients (Table 1) were randomly and equally divided into a CERE group and a control group. The 10MTWT (10-meter timed walking test) and 6MWT (6-minute walk test) were performed on all the subjects one day after the experiment started. At the same time, after one day lapsed, their VC (vital capacity), FVC (forced vital capacity), FEV1 (forced expiratory volume in one second), and chest expansion were measured. After the application of 
Table 1. General characteristics of subjects $(n=40)$

\begin{tabular}{lcc}
\hline & $\begin{array}{c}\text { CERE group } \\
(\mathrm{N}=20)\end{array}$ & $\begin{array}{c}\text { Control group } \\
(\mathrm{N}=20)\end{array}$ \\
\hline Gender (male/female) & $10 / 10$ & $11 / 9$ \\
Age (yrs) & $57.3 \pm 5.1^{\mathrm{a}}$ & $56.9 \pm 4.3$ \\
Height (cm) & $167.7 \pm 5.8$ & $168.6 \pm 7.8$ \\
Weight (kg) & $67 \pm 10.7$ & $70 \pm 12.4$ \\
Tobacco abuse & $45 \%$ & $40 \%$ \\
Paretic side (right/left) & $13 / 7$ & $14 / 6$ \\
Time since stroke (months) & $21 \pm 5.1$ & $22 \pm 5.4$ \\
Lesion type & $14 / 6$ & $13 / 7$ \\
(ischemic/hemorrhagic) & & \\
\hline
\end{tabular}

${ }^{a}$ Mean \pm SD; CERE: chest expansion resistance exercise

CERE, the same items were measured and compared with the pre-intervention values. Then 10MTWT and 6MWT were applied to the subjects, and the values before and after the intervention were compared. The control group conducted passive range of motion exercise within a range that would not affect respiratory function using lower extremity automatic instruments, while the intervention was applied to the CERE group. To facilitate respiration, CERE was applied to the CERE group based on the concept of proprioceptive neuromuscular facilitation (PNF). For CERE, patients lay on their side with the affected side upward, and the therapist placed both hands obliquely along the ribs from the apex of the lower ribs. For 5 minutes, the therapist trained each patient on inspiration using a quick stretch while breathing out completely. After the patient fully understood this process, the therapist applied resistance in caudal and medial directions in such a way as to cause responses in all ranges of motion but not to such a degree that movements were suppressed $^{7}$. This technique was applied to the CERE group for 20 minutes, and when a patient complained of dizziness or fatigue, the patient was allowed to rest until the symptoms disappeared. Using a tape measure, their lower chest expansion was measured. The 10th thoracic spinous process and the xiphoid process were marked with a pen, and the measurement was made during inspiration by linking the two marked points in parallel with the ground ${ }^{8)}$. As a tool for measurement in the pulmonary function test, a spirometer (EasyOne spirometer, ndd Medical Technologies, Zürich, Switzerland) was used; VC, FVC, and FEV1 were measured with it. The 10MTWT was applied to measure the time taken to move 10 meters $^{9}$. . To reduce errors from the acceleration and deceleration sections at the beginning and end of gait, the subjects were made to walk 14 meters, and the velocity for $10 \mathrm{~m}$ excluding the first $2 \mathrm{~m}$ and the last $2 \mathrm{~m}$ was measure ${ }^{10)}$. The $6 \mathrm{MWT}$ was used to measure the distance moved in 6 minutes ${ }^{11)}$. A track was drawn indoors, and a mark was made every 1 meter with tape. The length of the tape was measured to calculate the distance travelled in 6 minutes after the subject walked for 6 minutes. With this method, a stroke patient's muscle endurance and functional gait ability may be evaluated ${ }^{2}$.

Windows SPSS version 18.0 was used to analyze the data
Table 2. A comparison of chest expansion, VC, FVC, and $\mathrm{FEV}_{1}(\mathrm{n}=40)$

\begin{tabular}{lccc}
\hline & $\mathrm{n}$ & $\begin{array}{c}\text { Before } \\
\text { training }\end{array}$ & $\begin{array}{c}\text { After } \\
\text { training }\end{array}$ \\
\hline $\begin{array}{l}\text { Chest expansion (cm) } \\
\text { CERE group }\end{array}$ & 20 & $3.6 \pm 1.1^{\mathrm{a}}$ & $3.9 \pm 1.1^{*}$ \\
$\quad$ Control group & 20 & $3.6 \pm 1.2$ & $3.6 \pm 0.8$ \\
VC (L) & & & \\
CERE group & 20 & $2.7 \pm 0.4$ & $2.7 \pm 0.3$ \\
Control group & 20 & $2.8 \pm 0.3$ & $2.8 \pm 0.4$ \\
FVC (L) & & & \\
CERE group & 20 & $1.9 \pm 0.4$ & $2.0 \pm 0.4$ \\
Control group & 20 & $1.9 \pm 0.4$ & $1.9 \pm 0.4$ \\
FEV (L) & & & \\
CERE group & 20 & $1.5 \pm 0.4$ & $1.6 \pm 0.4$ \\
Control group & 20 & $1.6 \pm 0.3$ & $1.7 \pm 0.4$ \\
10MTWT (m/s) & & & \\
CERE group & 20 & $66.3 \pm 37.9$ & $64.0 \pm 35.9$ \\
Control group & 20 & $66.6 \pm 39.2$ & $65.3 \pm 39.5$ \\
6MWT (m) & & & \\
CERE group & 20 & $68.2 \pm 30.0$ & $70.3 \pm 29.1^{*}$ \\
Control group & 20 & $69.3 \pm 31.2$ & $70.1 \pm 32.3$ \\
\hline
\end{tabular}

${ }^{\mathrm{a}}$ Mean \pm SD. ${ }^{*} \mathrm{p}<0.05$. CERE: chest expansion resistance exercise; VC: vital capacity; FVC: forced vital capacity; $\mathrm{FEV}_{1}$ : force expiratory volume at one second; 10MTWT: 10-meter timed walking test; 6MWT: 6-minute walking test

for this research. The values of the CERE group and control group were expressed as means and standard deviations. A paired t-test was applied to compare changes between the CERE group and the control group after the exercise. A p-value less than 0.05 was considered to be statistically significant.

\section{RESULTS}

The clinical and demographic features of the patients are shown in Table 1. Prior to the experiment, there was no difference between the two groups in gender, age, height, weight, affected side, time after the onset of a stroke, lesion type, smoking rates, pulmonary functions $(\mathrm{VC}, \mathrm{FVC}$, and FEV1), 10MTWT result, 6MWT result, and chest expansion.

Table 2 shows the chest expansion values and VC, FVC, FEV1, 10MTWT, and 6MWT values measured before and after the intervention. The CERE group's chest expansion increased $(p<0.05)$, whereas the control group's chest expansion did not differ before and after the exercise. Both the control group and the CERE group saw no change in VC, FVC, and FEV1 after the exercise. In the 10MWT, neither group saw any change. However, in the 6MWT, the CERE group saw functional improvement, whereas the control group did not experience any significant improvement $(\mathrm{p}<0.05)$. 


\section{DISCUSSION}

To examine the effect of CERE, an exercise to facilitate respiration, VC, FVC, FEV1, and chest expansion were measured before and after CERE. To look at changes in functional gait ability, the 10MTWT and 6MWT were performed, and movement distances were measured and compared one day before and after CERE.

The result of CERE application was that the control group did not experience any significant change in chest expansion, whereas the CERE group experienced a significant change $(p<0.05)$. This was similar to the result of research $\left.{ }^{12}\right)$ that compared changes in chest expansion prior to and after the application of a PNF deep-breathing exercise to myotonic dystrophy patients, although there were numerical differences between the two studies. This result provides clinical grounds for the effects of a CERE intervention in facilitation of respiration, and other research results ${ }^{13-15)}$ that found that improved chest expansion capability translates into increased inflow of air into the lungs support the significance of the changes in this research.

Regarding VC, defined as the maximum amount of air a person can expel from the lungs after a maximum inspiration, the control group's change amount was 0.01 (L) and the CERE group's change amount was $0.4(\mathrm{~L})$, which were not statistically significant. Regarding FVC, defined as the volume change of the lung between a slow full inspiration to total lung capacity and a rapid maximal expiration to residual volume, the control group's change amount was $0.02(\mathrm{~L})$ and the CERE group's change amount was $0.11(\mathrm{~L})$, which were also not statistically significant. Regarding FEV1, defined as the maximum volume of air expired in one second, the control group's change amount was $0.02(\mathrm{~L})$ and the CERE group's change amount was $0.05(\mathrm{~L})$. Neither of these was statistically significant. Nonetheless, the CERE group's VC, FVC, and FEV1 numerically increased by more than those of the control group. This may be interpreted as meaning that CERE is not expected to have an immediate effect that improves pulmonary function but may have a positive influence on pulmonary function.

Reduced respiratory function is a crucial issue in stroke patients; decreased cardiopulmonary function among different types of damage makes up a large part of the disorders in chronic stroke patients and acts as an important factor, along with declined gait and movement ability, in their return to the community after rehabilitation treatment ${ }^{16,17)}$. Among the functional gait tests, the changes measured by the 10MTWT to evaluate gait velocity were not statistically significant in either group. In the 6-minute walking test to measure gait endurance, however, the control group's changes were not statistically significant, whereas the CERE group's changes were. Therefore, the importance of respiratory exercise in an approach to rehabilitation treatment intervention for stroke patients was verified, and addition of respiratory exercise to a rehabilitation treatment intervention program should be considered a priority. Future research needs to examine the minimum time period required for CERE to cause significant changes pulmonary function and chest expansion in stroke patients and to include a larger number of stroke patients with different ages as subjects.

\section{REFERENCES}

1) Teixeira-Salmela LF, Parreira VF, Britto RR, et al.: Respiratory pressures and thoracoabdominal motion in community-dwelling chronic stroke survivors. Arch Phys Med Rehabil, 2005, 86: 1974-1978. [Medline] [CrossRef]

2) Lanini B, Bianchi R, Romagnoli I, et al.: Chest wall kinematics in patients with hemiplegia. Am J Respir Crit Care Med, 2003, 168: 109-113. [Medline] [CrossRef]

3) Lee JH, Seo KC, Kim K: Measurement of changes in chest mobility and pulmonary functions in relation to stroke patient's positions. J Phys Ther Sci, 2012, 24: 253-256. [CrossRef]

4) Reid WD, Samrai B: Respiratory muscle training for patients with chronic obstructive pulmonary disease. Phys Ther, 1995, 75: 996-1005. [Medline]

5) Skinner JS: Exercise Testing \& Exercise Prescription for Special Cases: Theoretical Basis \& Clinical Application, 3rd ed. Philadelphia: Lippincott Williams \& Wilkins, 2005.

6) Courbon A, Calmels P, Roche F, et al.: Relationship between maximal exercise capacity and walking capacity in adult hemiplegic stroke patients. Am J Phys Med Rehabil, 2006, 85: 436-442. [Medline] [CrossRef]

7) Adler SS, Beckers D, Buck M: PNF in Practice: An Illustrated Guide, 3rd ed. Berlin: Springer-Verlag, 2008.

8) Bockenhauer SE, Chen H, Julliard KN, et al.: Measuring thoracic excursion: reliability of the cloth tape measure technique. J Am Osteopath Assoc, 2007, 107: 191-196. [Medline]

9) Hunt SM, McKenna SP, Williams J: Reliability of a population survey tool for measuring perceived health problems: a study of patients with osteoarthrosis. J Epidemiol Community Health, 1981, 35: 297-300. [Medline] [CrossRef]

10) Dean CM, Richards CL, Malouin F: Task-related circuit training improves performance of locomotor tasks in chronic stroke: a randomized, controlled pilot trial. Arch Phys Med Rehabil, 2000, 81: 409-417. [Medline] [CrossRef]

11) Cahalin LP, Mathier MA, Semigran MJ, et al.: The six-minute walk test predicts peak oxygen uptake and survival in patients with advanced heart failure. Chest, 1996, 110: 325-332. [Medline] [CrossRef]

12) Nitz J, Burke B: A study of the facilitation of respiration in myotonic dystrophy. Physiother Res Int, 2002, 7: 228-238. [Medline] [CrossRef]

13) Grimby G, Oxhoj H, Bake B: Effects of abdominal breathing on distribution of ventilation in obstructive lung disease. Clin Sci Mol Med, 1975, 48: 193-199. [Medline]

14) Roussos CS, Fixley M, Genest J, et al.: Voluntary factors influencing the distribution of inspired gas. Am Rev Respir Dis, 1977, 116: 457-467. [Medline]

15) Kim K, Fell DW, Lee JH: Feedback respiratory training to enhance chest expansion and pulmonary function in chronic stroke. J Phys Ther Sci, 2011, 23: 75-79. [CrossRef]

16) Hermann DM, Bassetti CL: Sleep-related breathing and sleep-wake disturbances in ischemic stroke. Neurology, 2009, 73: 1313-1322. [Medline] [CrossRef]

17) Goldie PA, Matyas TA, Evans OM: Deficit and change in gait velocity during rehabilitation after stroke. Arch Phys Med Rehabil, 1996, 77: 10741082. [Medline] [CrossRef] 